\title{
Efeito de extrato aquoso de Melia azedarach no desenvolvimento das fases imatura e reprodutiva de Spodoptera frugiperda (J. E. Smith, 1797) (Lepidoptera: Noctuidae)
}

\author{
Effect of Melia azedarach aqueous extract on the development of \\ immature and reproductive stages of Spodoptera frugiperda (J. E. \\ Smith, 1797) (Lepidoptera: Noctuidae)
}

\author{
Daniel Marchetti Maroneze ${ }^{1 *}$; Dileimar Machado Nalim Gallegos ${ }^{2}$
}

\section{Resumo}

Determinou-se, em condições de laboratório, o efeito de diferentes concentrações do extrato aquoso de Melia azedarach sobre a biologia de Spodoptera frugiperda. Folhas de milho foram imersas nos extratos $(0,1 \% ; 1,0 \%$ e $5,0 \%)$ e oferecidas a lagartas recém-eclodidas. Em doses elevadas $(1,0 \%$ e $5,0 \%$ ) os extratos causaram $100 \%$ de mortalidade larval. Observações das lagartas mortas indicaram mudas anormais e morte durante o processo de ecdise. Na concentração de $0,1 \%$ o extrato provocou o alongamento da fase larval e redução do peso das lagartas e pupas. Adultos provenientes de lagartas previamente intoxicadas com extrato a $0,1 \%$ apresentaram alterações em parâmetros reprodutivos tais como: número de ovos por fêmea, ovos por postura e viabilidade dos ovos. A fecundidade sofreu drástica redução. A sobrevivência dos ovos e a duração do período embrionário não foram afetadas em ensaios de atividade ovicida. Nenhum efeito foi observado em relação à atratividade alimentar de lagartas de primeiro ínstar em testes de arena com livre chance de escolha. Os resultados deste trabalho sugerem que o extrato aquoso de cinamomo apresenta potencial para o controle de S. frugiperda.

Palavras-chave: Lagarta do cartucho-do-milho, controle de pragas, inseticida botânico, cinamomo

\begin{abstract}
The effect of different concentrations of aqueous extracts of Melia azedarach on Spodoptera frugiperda biology was investigated under laboratory conditions. Corn leaves were immersed in solutions with extract concentrations of $0.1 \% ; 1.0 \%$ and $5.0 \%$ and offered to newly-born larvae. At higher doses $(1.0 \%$ and $5.0 \%)$ the extracts caused $100 \%$ mortality of larvae. Observations of dead larvae showed abnormal moults and death at ecdysis. At the concentration of $0.1 \%$, chinaberry extract increased the larval phase and reduced significantly the larval and pupal weight. Reproduction parameters, as the number of eggs per female, eggs per oviposition and eggs viability were affected using emerged adults from treated larvae with concentration of $0.1 \%$ Melia extract. The fecundity was drastically reduced. Survival and duration of egg stage were not affected by the extracts. No effect was observed in relation to attractiveness of caterpillars at first instar in tests with possibility of choice. The chinaberry aqueous extract showed good potential to be used as a control agent for $S$. frugiperda.
\end{abstract}

Key words: Fall armyworm, pest control, botanical insecticide, chinaberry

Acadêmico do Curso de Ciências Biológicas da UEL. Email: dm2x@yahoo.com.br

2 Bióloga, Doutora em Ciências Biológicas, Docente do Departamento de Biologia Animal e Vegetal da Universidade Estadual de Londrina. Email: dileimar@uel.br

Autor para correspondência 


\section{Introdução}

A lagarta-do-cartucho, Spodoptera frugiperda (J. E. Smith 1797) (Lepidoptera: Noctuidae), é considerada a principal praga da cultura do milho sendo responsável por perdas econômicas que podem chegar até $34 \%$ da produção (FIGUEIREDO; PENTEADO-DIAS, 2005). Esta espécie ocorre em todas as regiões brasileiras produtoras de milho e sua incidência é verificada tanto nos plantios de verão como nos cultivos de segunda época (safrinha) (VALICENTE, 2004; VALICENTE; VIANA; WAQUIL, 2004; VIANA et al., 2004; WAQUIL et al., 2004).

Atualmente, o controle deste inseto tem sido feito principalmente com inseticidas químicos (CRUZ, 2002). Entretanto, o uso intenso de defensivos agrícolas resulta em problemas sérios para o ambiente e para a saúde humana (MORAGAS; SCHNEIDER, 2003; COUTINHO et al., 2005), além de contribuir para o aparecimento de populações de insetos resistentes. Neste sentido, o desenvolvimento de novas medidas de combate às pragas é importante não apenas para aumentar o rendimento agrícola, mas também para minimizar os impactos ambientais e garantir o fornecimento de alimentos livres de resíduos tóxicos.

Nos últimos anos diversas estratégias de controle da lagarta-do-cartucho vêm sendo pesquisadas, destacando-se entre elas, o emprego de plantas com propriedades inseticidas (BORGONI; VENDRAMIM, 2003; SAITO et al., 2004; CÉSPEDES et al., 2005). Os inseticidas botânicos apresentam inúmeras vantagens quando comparados aos produtos sintéticos: são de fácil obtenção e uso, apresentam baixa persistência no ambiente, o desenvolvimento de resistência por parte dos insetos é lenta e a toxicidade a mamíferos é baixa (GALLO et al., 2002), além de colaborar com a redução dos custos da produção (ROEL, 2002).

Embora mais de 2000 espécies de plantas sejam conhecidas por suas características tóxicas
(VIEGAS JÚNIOR, 2003), a família botânica Meliaceae é atualmente muito investigada tanto pelo número de espécies com atividade inseticida como pela eficiência de seus aleloquímicos.

Assim, o objetivo deste trabalho foi avaliar, em condições de laboratório, o efeito de um extrato aquoso à base de folhas de Melia azedarach no desenvolvimento das fases imatura e reprodutiva de Spodoptera frugiperda.

\section{Material e Métodos}

Os experimentos foram conduzidos no laboratório de Entomologia do Centro de Ciências Biológicas (CCB) da Universidade Estadual de Londrina (UEL), sob condições controladas (temperatura de $25 \pm 2^{\circ} \mathrm{C}$, umidade relativa de $60 \pm 10 \%$ e fotofase de 14 horas) com a espécie Spodoptera frugiperda, mantida no laboratório em dieta artificial modificada de Perkins et al. (1973) e preparada de acordo com Nalim (1991). Foram testadas contra os insetos três concentrações do extrato: $0,1 \%, 1,0 \%$ e $5,0 \%$.

\section{Material vegetal}

Para o preparo dos extratos vegetais, folhas de Melia azedarach (coletadas nas margens do Lago Igapó 4 - Londrina, PR) (23 $18^{\prime} 58.40^{\prime \prime} \mathrm{S}-51^{\circ}$ $11^{\prime} 01.72$ ” O) foram secas em estufa $\left(50^{\circ} \mathrm{C}\right.$, por 48 h) e moídas em liquidificador comercial até a obtenção de um pó fino, o qual foi misturado a água destilada na proporção de 1 e $5 \mathrm{~g}$ por $100 \mathrm{ml}$ de água. As suspensões foram mantidas em frascos por $24 \mathrm{~h}$ e, posteriormente, filtradas através de um tecido fino ("voil"), obtendo-se os extratos aquosos a 1,0 e $5,0 \%$ (peso/volume), respectivamente. Para obtenção da concentração $0,1 \%$ optou-se pela diluição do extrato $1,0 \%$. Os extratos prontos foram acondicionados em vidros de cor âmbar e utilizados por um período máximo de $48 \mathrm{~h}$ após o preparo. 


\section{Efeito sobre os ovos}

Paraa determinação dopotencial ovicida, posturas provenientes de adultos da criação massal foram imersas durante 30 segundos nas três concentrações do extrato $(0,1 \%, 1,0 \%$ e 5,0\%). Posteriormente, foi retirado de cada postura, com um pincel fino sob microscópio estereoscópico, uma amostra contendo 50 ovos, colocados em placas de Petri de 9,5 cm de diâmetro contendo papel filtro umedecido com água destilada (controle) ou o extrato (tratamentos). Foram realizadas três repetições por tratamento, cada uma contendo 50 ovos. Os ensaios foram avaliados diariamente para determinar se a concentração do extrato interferia no período de incubação e viabilidade dos ovos. O grupo controle consistiu de ovos submersos em água destilada.

\section{Efeito sobre a fase de larva, pré-pupa e pupa}

Lagartas de primeiro ínstar provenientes de criação estoque, foram individualizadas em tubos de ensaio com fundo chato $(2,5 \mathrm{~cm}$ de diâmetro por $8,0 \mathrm{~cm}$ de altura) tampados com algodão hidrófilo e alimentadas diariamente, durante toda a fase larval, com secções de folhas de milho de 20 a 40 dias de idade (genótipo DKB 330). Antes de serem oferecidas às lagartas as folhas foram lavadas em água corrente, secas com uma toalha de papel e recortadas em secções de $5 \mathrm{~cm}$. Posteriormente foram submersas nos extratos a diferentes concentrações $(0,1 \%, 1,0 \%$ e 5,0\%) por 30 segundos e mantidas ao ar livre por aproximadamente 15 minutos para a evaporação do excesso de água. No controle, os fragmentos foliares foram imersos em água destilada.

O desenvolvimento dos insetos foi acompanhado diariamente avaliando-se os seguintes parâmetros: duração do período, viabilidade, peso com 10 e 15 dias de idade, número de ínstares e duração de cada ínstar(fase de larva); duração do período eviabilidade (fase de pré-pupa); duração do período, peso com 24 horas de idade, viabilidade e razão sexual (fase de pupa). Cada tratamento constou de 30 lagartas, sendo considerado como repetições médias de 10 lagartas. Para a determinação do número de ínstares foram utilizadas 15 lagartas extras por tratamento, mensurando-se, diariamente, a largura da cápsula cefálica através de uma ocular graduada acoplada a um microscópio estereoscópico. As pupas foram sexadas de acordo com a técnica de Butt e Cantu (1962), determinando-se a razão sexual através da fórmula: $r s=$ 우 / $($ 우 + 令 $)$.

\section{Efeito sobre a atratividade alimentar}

Secções de folhas $\left(4 \mathrm{~cm}^{2}\right)$ de milho de 30 dias de idade foram submersas por 30 segundos nos extratos em diferentes concentrações $(0,1 \%, 1,0 \%$ e 5,0\%). Após secarem ao ar livre, os fragmentos foliares foram oferecidos às lagartas em um teste de dupla escolha e dispostos em quatro pontos eqüidistantes entre si e próximos da margem da placa de Petri de $15 \mathrm{~cm}$ de diâmetro, constituindose cada conjunto destes uma arena. Assim, em cada arena, foram mantidos, em pontos opostos, duas secções foliares com extrato e duas submersas em água destilada (testemunha). Foram liberadas 50 lagartas de primeiro ínstar no centro de cada arena, avaliando-se após 24 horas, a porcentagem de lagartas presentes em cada disco. Foram realizadas 5 repetições por concentração.

\section{Efeito sobre a fase adulta}

Adultos virgens e de mesma idade provenientes de lagartas previamente intoxicadas durante toda a fase larval foram utilizados para avaliação dos seguintes parâmetros: longevidade, período de préoviposição, período de oviposição, período pósoviposição, número de posturas por fêmea, número de ovos por postura, total de ovos por fêmea, número de cópulas (medido pelo número de espermatóforos na bolsa copuladora das fêmeas) e porcentagem de fecundidade. A fecundidade foi determinada através da fórmula: [ $n^{\circ}$ de ovos das fêmeas tratadas $/ n^{\circ}$ de ovos das fêmeas controle] x 100 . 
Os casais, mantidos em gaiolas de PVC, foram alimentados com solução de mel a $10 \%$. Os ovos foram retirados do papel que forrava o interior das gaiolas e contados diariamente. Para a estimativa da viabilidade, foi considerada o segundo dia de postura por casal, sendo retirado uma amostra de 50 ovos.

Após a morte dos adultos, as fêmeas copuladas foram separadas e o número de espermatóforos contados, utilizando-se a técnica de Brown e Dewhurst(1975). Foram realizadas cinco repetições por tratamento, sendo cada casal considerado uma repetição.

\section{Análise estatística}

O delineamento experimental adotado nos testes foi inteiramente casualizado sendo os resultados submetidos à análise de variância e as médias comparadas pelo Teste de Tukey, ao nível de 5\% de probabilidade através do programa ASSISTAT versão 7.4 Beta.

\section{Resultados e Discussão}

Efeito sobre os ovos

Não foi verificado efeito tóxico do extrato aquoso na viabilidade dos ovos da lagarta do cartucho do milho (Tabela 1). Os valores registrados foram superiores a $82,5 \%$ em todos os ensaios, semelhantemente ao encontrado por Nalim (1991), quando estudou a biologia de $S$. frugiperda, em laboratório.

O período de incubação, para todos os tratamentos, foi em média de 3,19 dias, não havendo diferença estatística significativa entre eles (Tabela 2).

Resultados semelhantes a este trabalho foram descritos por Thomazini, Vendramim e Lopes (2000) ao avaliar o potencial ovicida de extrato aquoso de folhas de Trichillia pallida sobre Tuta absoluta (Lepidoptera: Gelechiidae). Nas concentrações testadas $(1,0 \%$ e $5,0 \%)$, a sobrevivência da fase embrionária do inseto não foi afetada.

De maneira geral, o revestimento dos ovos dos insetos consiste de duas camadas, uma externa denominada córion e outra interna, a membrana vitelínica. Entre elas comumente ocorre uma camada lipídica ou cerosa, cuja função é impedir a perda de água pelo embrião (MARGARITIS; MAZZINI, 1998). Provavelmente, esta estrutura hidrofóbica dificulta a penetração dos compostos hidrossolúveis tóxicos até o interior do ovo, independentemente da concentração do extrato.

Tabela 1. Viabilidade média de ovos de S. frugiperda ( \pm EP) submetidos a diferentes concentrações do extrato aquoso de folhas de M. azedarach.

\begin{tabular}{cc}
\hline \multicolumn{3}{c}{ Viabilidade (\%) $^{\mathbf{1}}$} \\
\hline Controle & $96,6 \pm 3,05 \mathrm{a}$ \\
$0,1 \%$ & $91,3 \pm 4,61 \mathrm{a}$ \\
$1,0 \%$ & $82,6 \pm 11,71 \mathrm{a}$ \\
$5,0 \%$ & $89,3 \pm 3,05 \mathrm{a}$ \\
\hline
\end{tabular}

${ }^{1}$ Médias seguidas pela mesma letra na coluna não diferem estatisticamente entre si pelo teste de Tukey a $5 \%$ de probabilidade 
Tabela 2. Duração do período embrionário de ovos de S. frugiperda ( \pm EP) submetidos a diferentes concentrações do extrato aquoso de folhas de M. azedarach.

\begin{tabular}{cc}
\hline \multicolumn{2}{c}{ Duração (dias) $^{\mathbf{1}}$} \\
\hline Controle & $3,00 \pm 0,00 \mathrm{a}$ \\
$0,1 \%$ & $3,00 \pm 0,00 \mathrm{a}$ \\
$1,0 \%$ & $3,43 \pm 0,41 \mathrm{a}$ \\
$5,0 \%$ & $3,34 \pm 0,43 \mathrm{a}$ \\
\hline
\end{tabular}

${ }^{1}$ Médias seguidas pela mesma letra na coluna não diferem estatisticamente entre si pelo teste de Tukey a $5 \%$ de probabilidade

Efeito sobre a fase larval

Nenhuma lagarta de S. frugiperda alimentada com folhas tratadas com as concentrações $1,0 \%$ e $5,0 \%$ do extrato aquoso de $M$. azedarach completou a fase larval. Registrou-se mortalidade total antes que elas atingissem 10 dias de idade, principalmente durante os ínstares iniciais. Dessa forma, o único parâmetro registrado para estes tratamentos foi a viabilidade larval.

Tais resultados vêm a confirmar a atividade inseticida de $M$. azedarach já referida para outros lepidópteroscomoTutaabsoluta(BRUNHEROTTO; VENDRAMIM, 2001) e Plutella xylostella (TORRES et al., 2006). No que se refere à $S$. frugiperda, o extrato empregado nesse trabalho foi tão eficiente quanto os extratos aquosos de folhas de Trichila pallens e Azadirachta indica, os quais, avaliados na concentração 5\%, apresentaram efeito significativo (98,7\% de mortalidade) sobre o inseto (BORGONI; VENDRAMIM, 2003).

À concentração $0,1 \%$, ocorreu alongamento da fase larval e redução do peso em relação ao controle. Lagartas intoxicadas apresentaram peso médio de 7,9 e 52,9 mg aos 10 e 15 dias de idade e duração média de 25,7 dias enquanto a testemunha apresentou peso médio de 57,4 e 567,7 mg e duração média de 15,8 dias. A viabilidade não foi alterada (Tabela 3 e Figura 1).

Tabela 3. Peso, duração e viabilidade média ( \pm EP) da fase larval de $S$. frugiperda alimentada com folhas de milho tratadas com extrato aquoso a base de folhas de M. azedarach.

\begin{tabular}{ccccc}
\hline & \multicolumn{2}{c}{ Peso $^{\mathbf{~}} \mathbf{( m g )}$} & Duração $^{\mathbf{1}}$ (dias) & Viabilidade \\
\cline { 2 - 3 } & $\mathbf{1 0}^{\mathbf{0}} \mathbf{~ d i a}$ & $\mathbf{1 5}^{\mathbf{0}} \mathbf{~ d i a}$ & & \\
\hline Controle & $57,4 \pm 4,04 \mathrm{a}$ & $567,7 \pm 6,23 \mathrm{a}$ & $15,8 \pm 0,07 \mathrm{a}$ & $86,6 \pm 5,77 \mathrm{a}$ \\
$0,1 \%$ & $7,9 \pm 1,69 \mathrm{~b}$ & $52,5 \pm 11,9 \mathrm{~b}$ & $25,7 \pm 1,71 \mathrm{~b}$ & $53,2 \pm 21,5 \mathrm{a}$ \\
$1,0 \%$ & - & - & - & $0,00^{* *}$ \\
$5,0 \%$ & - & - & - & $0,00 * *$ \\
\hline
\end{tabular}

${ }^{1}$ Médias seguidas pela mesma letra na coluna não diferem entre si, pelo teste de Tukey, ao nível de $5 \%$ de probabilidade. $* *$ Dados não incluídos na analise estatística (variância nula). 


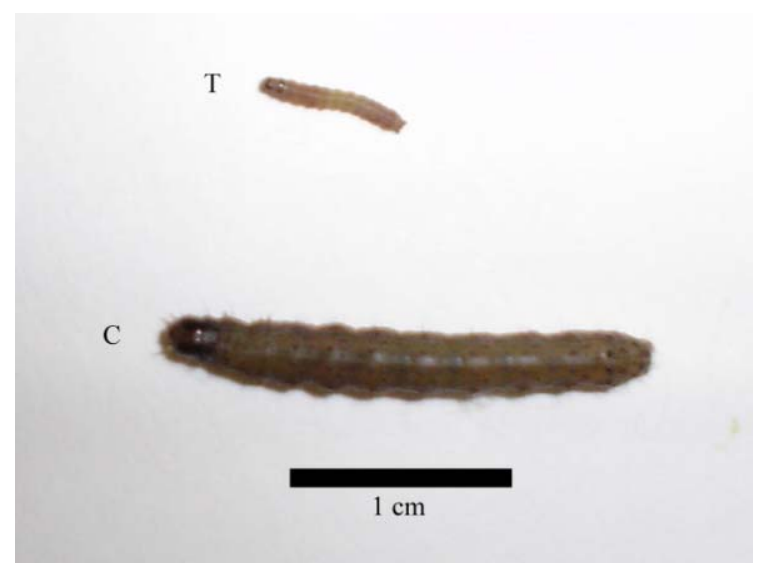

Figura 1. Lagartas de $S$. frugiperda com dez dias de idade, tratada e não tratada com extrato de $M$. azedarach 0,1\%. T: Tratamento; C: Controle.

O número de ínstares larvais, entretanto, também sofreu alteração. Lagartas alimentadas com folhas imersas no extrato apresentaram 7 ínstares, enquanto as testemunhas passaram apenas por 6 . A duração dos ínstares no tratamento foi em média superior ao observado para o grupo controle (Tabela 4). Comparando-se a largura da cápsula cefálica dentro do mesmo ínstar registrou-se que esta foi em média maior no controle do que no tratamento (Tabela 5). A razão de crescimento obtida em ambos os tratamentos obedeceu à regra de Dyar (1890), encontrando-se no intervalo estabelecido por esse autor, que varia de 1,1 a 1,9 .

Torres, Barros e Oliveira (2001) também registraram prolongamento da fase larval do lepidóptero Plutella xylostela pelo efeito de extrato de $M$. azedarach, atribuindo este fato à presença de inibidores de crescimento ou substâncias tóxicas no extrato. Ressaltaram que em condições de campo o alongamento é importante, uma vez que isso pode aumentar o tempo de exposição da praga aos inimigos naturais, bem como o tempo médio de cada geração, reduzindo o crescimento populacional.

A redução do peso relaciona-se à pouca ingestão de alimento, por existir nos extratos compostos inibidores da alimentação (HUANG et al., 1996; CARPINELLA et al., 2002). Extratos desta meliácea também promovem em $S$. frugiperda a ativação do sistema citocromo P-450, um importante mecanismo de degradação de metabólitos tóxicos (BREUER et al., 2003), desviando, dessa maneira, recursos que normalmente seriam utilizados para ganho de biomassa (TORRECILLAS; VENDRAMIM, 2001).

Em Spodoptera littoralis há registros de que o extrato de $M$. azedarach promove a destruição das células epiteliais do intestino, restringido a digestão e absorção de alimento (SCHMIDIT; AHMED; BREUER, 1997), enquanto em Cnaphalocrocis medinalis ocorrem reduções acentuadas no nível de enzimas digestivas e na movimentação peristáltica (NATHAN, 2006).

Outro aspecto observado neste trabalho, principalmente nas concentrações mais elevadas, foi que muitas lagartas morreram durante a ecdise sem conseguir liberar totalmente a exúvia e a cápsula cefálica (Figura 2). Sintomas semelhantes foram relatados por Mordue e Nisbet (2000) em insetos intoxicados com azadiractina. De acordo com os autores, esse aleloquímico promove redução nos níveis de ecdisônio. 
Tabela 4. Duração dos instares larvais de S. frugiperda alimentada com folhas de milho tratadas com extrato aquoso a base de folhas de M. azedarach

\begin{tabular}{ccc}
\hline \multirow{2}{*}{ Instar } & Controle & Extrato 0,1 \% \\
\cline { 2 - 3 } & Duração (dias) & Duração (dias) \\
\hline I & $3,00 \pm 0,00$ & $3,00 \pm 0,00$ \\
II & $2,00 \pm 0,00$ & $2,23 \pm 0,43$ \\
IV & $2,00 \pm 0,00$ & $2,61 \pm 0,50$ \\
V & $2,15 \pm 0,37$ & $2,46 \pm 0,51$ \\
VI & $2,84 \pm 0,37$ & $2,76 \pm 0,59$ \\
VII & $2,00 \pm 0,00$ & $3,69 \pm 0,48$ \\
\hline
\end{tabular}

Tabela 5. Largura média da cápsula cefálica e razão de crescimento (RC) dos instares larvais de S. frugiperda alimentada com folhas de milho tratadas com extrato aquoso a base de folhas de M. azedarach

\begin{tabular}{|c|c|c|c|c|}
\hline \multirow[b]{2}{*}{ Instar } & \multicolumn{2}{|l|}{ Controle } & \multicolumn{2}{|c|}{ Extrato 0,1\% } \\
\hline & $\begin{array}{c}\text { Largura da cápsula } \\
\text { cefálica }(\mathbf{m m})\end{array}$ & $\mathbf{R C}$ & $\begin{array}{c}\text { Largura da cápsula } \\
\text { cefálica }(\mathbf{m m})\end{array}$ & $\mathbf{R C}$ \\
\hline $\mathbf{I}$ & $0,30 \pm 0,00$ & 1,72 & $0,30 \pm 0,00$ & 1,72 \\
\hline II & $0,51 \pm 0,02$ & 1,59 & $0,46 \pm 0,03$ & 1,37 \\
\hline III & $0,82 \pm 0,02$ & 1,65 & $0,70 \pm 0,03$ & 1,45 \\
\hline IV & $1,36 \pm 0,02$ & 1,50 & $1,02 \pm 0,06$ & 1,42 \\
\hline $\mathbf{V}$ & $2,06 \pm 0,03$ & 1,40 & $1,46 \pm 0,10$ & 1,38 \\
\hline VI & $2,89 \pm 0,05$ & & $2,03 \pm 0,14$ & 1,30 \\
\hline VII & - & & $2,64 \pm 0,20$ & \\
\hline \multicolumn{2}{|c|}{ Média da razão de crescimento } & 1,57 & & 1,44 \\
\hline
\end{tabular}

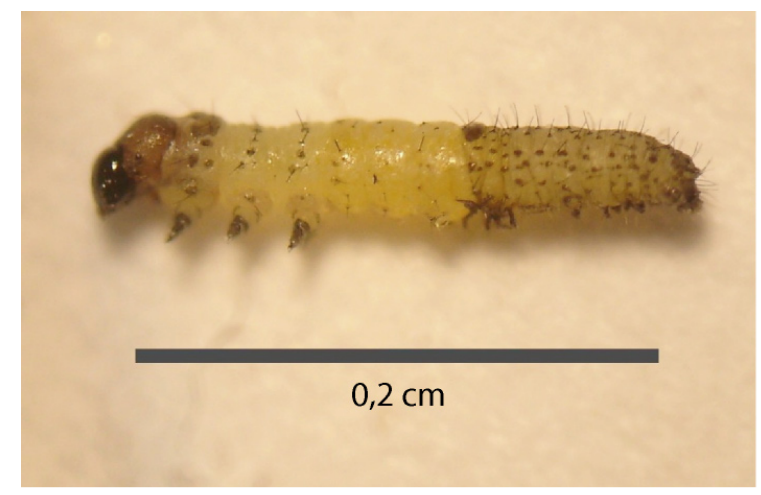

Figura 2. Lagarta de $S$. frugiperda morta durante a ecdise sem conseguir liberar a exúvia e a cápsula cefálica. 


\section{Efeito sobre a atratividade alimentar}

Apesar da livre chance de escolha entre os fragmentos foliares, nas concentrações testadas $(0,1 \%, 1,0 \%$ e $5,0 \%)$, o extrato não exerceu efeito significativo sobre a preferência alimentar das lagartas de primeiro ínstar. A porcentagem de lagartas nas secções tratadas e não tratadas não diferiram estatisticamente (Tabela 6).

Estudo sobre a atratividade de lagartas neonatas de Ascia monuste orseis em discos de folhas de couve imersos em extratos aquosos de Azadirachta indica e Sapindus saponaria, também não revelou diferença após 24 horas no número médio de lagartas sobre os discos tratados e não tratados; entretanto, o efeito de $S$. saponaria foi positivo em lagartas de terceiro ínstar (MEDEIROS; BOIÇA JÚNIOR, 2005).
Em Spodoptera frugiperda, há registro de forte efeito repelente de extratos de sementes de $A$. indica (HERNANDEZ, 1995). De modo geral, os insetos são capazes de diferenciar partes da planta tratadas e não tratadas com extrato de $A$. indica, e à medida que novas folhas não tratadas tornam-se disponíveis, as lagartas podem voltar a alimentar-se em partes não protegidas e acarretar danos ao milho (VIANA; PRATES, 2003).

Neste sentido, a princípio, a ausência de efeito repelente do extrato de $M$. azedarach sobre $S$. frugiperda poderia favorecer a integridade de plantas tratadas com estas soluções, uma vez que as lagartas não seriam atraídas para as folhas não protegidas; porém, para que o efeito sobre a atratividade alimentar seja melhor avaliado, estudos envolvendo diferentes ínstares são necessários.

Tabela 6. Atratividade de lagartas de primeiro ínstar de S. frugiperda por extrato aquoso a base de folhas de $M$. azedarach

\begin{tabular}{ccc}
\hline $\mathbf{N}^{\mathbf{0}}$ do ensaio & Concentração & Lagartas atraídas (\%) $^{\mathbf{1}}$ \\
\hline 1 & Extrato $0,1 \%$ & $59,0 \mathrm{a}$ \\
& Controle & $41,0 \mathrm{a}$ \\
2 & Extrato $1,0 \%$ & $57,4 \mathrm{a}$ \\
& Controle & $42,6 \mathrm{a}$ \\
3 & Extrato $5,0 \%$ & $56,2 \mathrm{a}$ \\
& Controle & $43,8 \mathrm{a}$ \\
\hline
\end{tabular}

${ }^{1}$ Médias seguidas da mesma letra, dentro do mesmo ensaio, não diferem entre si, pelo teste de Tukey, ao nível de $5 \%$ de probabilidade

Efeito sobre a fase de pré-pupa

Pré-pupas oriundas de lagartas alimentadas com folhas de milho contendo extrato $(0,1 \%)$ completaram esta fase em três dias, valor superior ao constatado para aquelas providas de lagartas não intoxicadas. A viabilidade não sofreu alteração (Tabela 7). Não foram encontrados registros de estudos relatando o efeito de compostos vegetais sobre esta fase do ciclo biológico, uma vez que os autores consideram-na juntamente com a fase larval. Assim, possivelmente, o prolongamento registrado ocorra em função de fatores similares ao discutido para a fase larval. 
Tabela 7. Duração e viabilidade média $( \pm$ EP) da fase de pré-pupa de S. frugiperda alimentada com folhas de milho tratadas com extrato aquoso a base de folhas de M. azedarach.

\begin{tabular}{ccc}
\hline & Duração $^{\mathbf{1}}$ (dias) & Viabilidade $^{\mathbf{1}(\%)}$ \\
\hline Controle & $2,0 \pm 0,06 \mathrm{a}$ & $96,0 \pm 6,87 \mathrm{a}$ \\
$0,1 \%$ & $3,0 \pm 0,32 \mathrm{~b}$ & $100,0 \pm 0,0 \mathrm{a}$ \\
$1,0 \% *$ & - & - \\
$5,0 \% *$ & - & - \\
\hline
\end{tabular}

${ }^{1}$ Médias seguidas pela mesma letra na coluna não diferem entre si, pelo teste de Tukey, ao nível de $5 \%$ de probabilidade. *Não houve formação de pré-pupas.

\section{Efeito sobre a fase pupal}

As pupas provenientes de lagartas intoxicadas (extrato $0,1 \%$ ) não apresentaram diferenças em relação ao controle quanto à duração do período de desenvolvimento, viabilidade e razão sexual (Tabela 8).

Uma provável explicação para a elevada sobrevivência das pupas (100\%) seria que o efeito de plantas inseticidas na sobrevivência dos insetos é mais drástico na fase larval do que pupal, uma vez que é na fase de larva que o inseto ingere as substâncias químicas presentes no alimento (RODRÍGUEZ; VENDRAMIM, 1996). Boiça Júnior et al. (2005), trabalhando com diversas plantas, também não constataram efeito negativo de extratos vegetais sobre a duração e viabilidade da fase pupal do lepidóptero Plutella xylostella.
Apenas o peso foi afetado adversamente pelo extrato, registrando-se um valor médio de 226,6 mg (controle) e 166,4 mg (testemunha), com redução de $26 \%$ (Tabela 8 ). O peso das pupas está diretamente relacionado ao desempenho do inseto na fase larval, uma vez que à medida que o consumo foliar pelas lagartas aumenta, as pupas também aumentam de peso (LIMA et al., 2006). De acordo com Huang et al. (1995), Carpinella et al. (2003) e Saito et al. (2004), a espécie M. azedarach produz uma série de compostos químicos, muitos com ação de inibição alimentar, explicando, dessa forma, a interrupção total da alimentação observada nas concentrações maiores $(1,0 \%$ e 5,0\%) em que não se obteve pupas, assim como a baixa ingestão de alimento pelas lagartas intoxicadas com extrato a $0,1 \%$.

Tabela 8. Peso com 24 horas, duração, viabilidade média ( \pm EP) e razão sexual da fase pupal de S. frugiperda alimentada com folhas de milho tratadas com extrato aquoso a base de folhas de M. azedarach.

\begin{tabular}{ccccc}
\hline & Peso $(\mathbf{m g})^{\mathbf{1}}$ & Duração $^{\mathbf{1}}$ (dias) & Viabilidade $^{\mathbf{1}} \mathbf{( \% )}$ & Razão sexual $^{\mathbf{1}}$ \\
\hline Controle & $226,6 \pm 1,65 \mathrm{a}$ & $10,6 \pm 0,30 \mathrm{a}$ & $95,8 \pm 7,21 \mathrm{a}$ & $0,59 \mathrm{a}$ \\
$0,1 \%$ & $166,4 \pm 19,02 \mathrm{~b}$ & $10,0 \pm 0,50 \mathrm{a}$ & $100 \pm 0,00 \mathrm{a}$ & $0,56 \mathrm{a}$ \\
$1,0 \% *$ & - & - & - & - \\
$5,0 \% *$ & - & - & - & - \\
\hline
\end{tabular}

${ }^{1}$ Médias seguidas pela mesma letra na coluna não diferem entre si, pelo teste de Tukey, ao nível de 5\% de probabilidade. * Não houve formação de pupas.

\section{Efeitos sobre a fase adulta}

Dos casais avaliados, não se registrou diferença estatística em relação ao controle quanto ao período de pré-oviposição, oviposição, pósoviposição, número de postura/fêmea, número de espermatóforos/fêmea e longevidade dos adultos (Tabela 9).

O período de pré-oviposição, oviposição e pós-reprodutivo foram em média de 6,0, 9,4 e 2,0 dias para o controle e de $8,8,7,8$ e 1,4 dias para 
os tratamentos. Embora não tenha sido detectada diferença nestes parâmetros biológicos, Schmidt et al. (1997), ao intoxicarem lagartas de Spodoptera littoralis com extrato metanólico de $M$. azedarach, relataram aumento no período de pré-oviposição e redução no período de oviposição.

Verificou-se que o número médio de espermatóforos transferidos para a bolsa copuladora das fêmeas foi de 1,0 para indivíduos provenientes de lagartas intoxicadas e de 2,4 para a testemunha. A porcentagem de acasalamento nas duas condições estudadas foi de $100 \%$, uma vez que todas as fêmeas analisadas apresentaram no mínimo 1 espermatóforo. Desses resultados, pode-se deduzir que o extrato não interfere na cópula dos adultos.

Quanto à longevidade, machos e fêmeas controle viveram em média 20,8 e 17,4 dias, respectivamente, enquanto o tratamento 16,4 e 17,8 dias.

De modo geral, adultos não morrem pela ação dos derivados de Azadirachta indica, considerada a espécie vegetal mais importante e promissora no controle de pragas, entretanto, essas substâncias são capazes de interferir na reprodução dos insetos, seja por redução da fecundidade ou esterilização total (SCHMUTTERER, 1990). Osresultados encontrados nesta pesquisa corroboram esta afirmação. Dentre os parâmetros afetados negativamente pelo extrato destacam-se o número de ovos por fêmea, número de ovos por postura e a viabilidade dos ovos (Tabela 9). Enquanto as fêmeas controle ovipositaram em média 2.540 ovos, aquelas oriundas de lagartas intoxicadas com extrato $0,1 \%$ ovipositaram apenas 933 ovos. O número de ovos por postura foi de 174 com viabilidade média de $95 \%$ para o controle e de 92 com viabilidade de $40 \%$ para a testemunha.

Costa, Silva e Fiuza (2004) observaram que a quantidade e qualidade de nutrientes obtidos durante a alimentação larval pode influenciar o número de ovaríolos por ovário e, por extensão, reduzir o potencial de produção de ovos. Destacaram também que algumas espécies de insetos não se alimentam durante a fase adulta, ou utilizam recursos de baixa qualidade nutricional, tornando-se, portanto, dependentes das reservas protéicas acumuladas pelas larvas. Assim, larvas que consomem dietas ricas em proteínas produzem pupas mais pesadas e adultos que produzem mais ovos que os insetos alimentados com dietas pobres.

A campo, a redução do número de ovos e da taxa de eclosão pode influenciar diretamente o número de indivíduos na fase seguinte do ciclo biológico, ou seja, a fase larval. Com menos lagartas eclodindo, menor será o consumo de alimento, reduzindo assim os danos à lavoura de milho.

Tabela 9. Parâmetros reprodutivos de adultos de S. frugiperda provenientes de lagartas intoxicadas com extrato aquoso a base de folhas de M. azedarach

\begin{tabular}{|c|c|c|}
\hline Variáveis $^{1}$ & Controle & Extrato 0,1\% \\
\hline Longevidade dos machos $^{* *}$ & $20,8 \pm 4,44 \mathrm{a}$ & $17,4 \pm 6,30 \mathrm{a}$ \\
\hline Longevidade das fêmeas** & $17,4 \pm 1,81 \mathrm{a}$ & $17,8 \pm 1,30 \mathrm{a}$ \\
\hline Pré-oviposição** & $6,0 \pm 1,87 \mathrm{a}$ & $8,8 \pm 2,16 \mathrm{a}$ \\
\hline Oviposição** & $9,4 \pm 2,88 \mathrm{a}$ & $7,8 \pm 3,96 \mathrm{a}$ \\
\hline Pós-oviposição ${ }^{* *}$ & $2,0 \pm 2,04 \mathrm{a}$ & $1,4 \pm 1,67 \mathrm{a}$ \\
\hline Ovos/fêmea & $2540,0 \pm 540,00 \mathrm{a}$ & $933,6 \pm 484,62 b$ \\
\hline Posturas/fêmea & $16,0 \pm 5,70 \mathrm{a}$ & $10,6 \pm 6,42 \mathrm{a}$ \\
\hline Ovos/postura & $174,5 \pm 65,76 \mathrm{a}$ & $92,4 \pm 41,78 b$ \\
\hline Viabilidade $\left(2^{\mathrm{a}} \text { postura }\right)^{* * *}$ & $95,2 \pm 9,65 \mathrm{a}$ & $40,0 \pm 18,92 b$ \\
\hline Espermatóforos/fêmea & $2,4 \pm 1,67 \mathrm{a}$ & $1,0 \pm 0,00 \mathrm{a}$ \\
\hline$\%$ Fecundidade, comparado ao controle & - & 37,0 \\
\hline
\end{tabular}

${ }^{1}$ Médias seguidas pela mesma letra na linha não diferem estatisticamente entre si pelo teste de Tukey a $5 \%$ de probabilidade. $* *$ (dias). $* * *(\%)$. 


\section{Conclusões}

$\mathrm{O}$ extrato aquoso de folhas de Melia azedarach provoca mortalidade total de lagartas de Spodoptera. frugiperda nas concentrações de 1 e 5\%;

$\mathrm{Na}$ concentração de $0,1 \%$, o extrato afeta negativamente o peso de lagartas e pupas e reduz acentuadamente a fecundidade dos adultos;

$\mathrm{O}$ extrato estudado não apresenta efeito ovicida e repelente sobre lagartas neonatas.

\section{Agradecimentos}

À bióloga Elisa Cimitan Mendes pelo apoio e ao Prof. Dr. Moacyr Medri pelo empréstimo de equipamentos.

\section{Referências}

BORGONI, P. C.; VENDRAMIM, J. D. Bioatividade de extratos aquosos de Trichilia spp. sobre Spodoptera frugiperda (J. E. Smith) (Lepidoptera: Noctuidae) em milho. Neotropical Entomology, Londrina, v. 32, n. 4, p. 665-669, out./dez. 2003.

BOIÇA JUNIOR, A. L.; MEDEIROS, C. A. M.; TORRES, A. L.; CHAGAS-FILHO, N. R. Efeito de extratos aquosos de plantas no desenvolvimento de Plutella xylostella (L.) (Lepidoptera: Plutellidae) em couve. Arquivos do Instituto Biológico, São Paulo, v. 72, n. 1, p. 45-50, jan./mar. 2005.

BREUER, M.; HOSTE, B.; DE LOOF, A.; NAGVI, S. N. H. Effect of Melia azedarach extract on the activity of NADPH-cytochrome c reductase and cholinesterase in insects. Pesticide Biochemistry and Physiology, San Diego, v. 76, n. 3, p. 99-103, Jul. 2003.

BROWM, E. S.; DEWHURST, C. F. The genus Spodoptera (Lepidoptera, Noctuidae) in Africa and the Near East. Bulletin of Entomological Research, Famham Royal, v. 65, n. 2, p. 221-262, 1975.

BRUNHEROTTO, R.; VENDRAMIM, J. D. Bioatividade de extratos aquosos de Melia azedarach L. sobre o desenvolvimento de Tuta absoluta (Meyrick) (Lepidoptera: Gelechiidae) em tomateiro. Neotropical Entomology, Londrina, v. 30, n. 3, p. 455-459, set. 2001.

BUTT, B. A.; CANTU, E. Sex determination of lepidopterous pupae. Washington: USDA/ARS, 1962.
CARPINELLA, M.C.; DEFAGO, M. T.; VALLADARES, G.; PALACIOS, S. M. Antifeedant and Insecticide properties of a limonoid from Melia azedarach (Meliaceae) with potential use for pest management. Journal of Agricultural and Food Chemistry, Easton, v. 51, n. 2, p. 369-374, Jan. 2003.

CARPINELLA,M.C.;FERRAYOLI,C.;VALLADARES, G.; DEFAGO, M.; PALACIOS, S. Potent limonoid insect antifeedant from Melia azedarach. Bioscience, Biotechnolog and Biochemistry, Tokyo, v. 66, n. 8, p. 1731-1736, Aug. 2002.

CÉSPEDES, C. L.; SALAZAR, J. R.; MARTINEZ, M.; ARANDA, E. Insect growth regulatory effects of some extracts and sterols from Myrtillocactus geometrizans (Cactaceae) against Spodoptera frugiperda and Tenebrio molitor. Phytochemistry, New York, v. 66, n. 20, p. 24812493, Oct. 2005.

COSTA, E. L. N.; SILVA, R. F. P.; FIUZA, M. L. Efeitos, aplicações e limitações de extratos de plantas inseticidas. Acta Biologia Leopoldensia, São Leopoldo, v. 26, n. 2, p. 173-185, jul./dez. 2004.

COUTINHO, C. F. B.; TANIMOTO, S. T.; GALLI, A.; GARBELLINI, G. S.; TAKAYAMA, M.; AMARAL, R. B.; MAZO, L. H.; AVACA, L. A.; MACHADO, S. A. S. Pesticidas: mecanismo de ação, degradação e toxidez. Pesticidas: Revista de Ecotoxicologia e Meio Ambiente, Curitiba, v. 15, p. 65-72, jan./dez. 2005.

CRUZ, I. Manejo da resistência de insetos-praga a inseticidas, com ênfase em Spodoptera frugiperda (Smith). Sete Lagoas: Embrapa Milho e Sorgo, 2002. (Documentos, 21).

DYAR, H. G. The number of molts of lepidopterous larvae. Psyche, Heidelberg, v. 5, p. 420-422, 1890.

FIGUEIREDO, M. L. C.; PENTEADO-DIAS, A. M. Danos provocados por Spodoptera frugiperda na produção de matéria seca e nos rendimentos de grãos, na cultura do milho. Sete Lagoas: Embrapa Milho e Sorgo, 2005. (Comunicado Técnico, 130).

GALLO, D.; NAKANO, O.; SILVEIRA-NETO, S.; CARVALHO, R. P. L.; BAPTISTA, G. C.; BERTIFILHO, E.; PARRA, J. R. P.; ZUCCHI, R. A.; ALVES, S. B.; VENDRAMIM, J. D.; MARCHINI, L. C.; LOPES, J. R S.; OMOTO, C. Entomologia agrícola. Piracicaba: FEALQ, 2002.

HERNÁNDEZ, C. R. Efeito de extratos aquosos de Meliaceae no desenvolvimento de Spodoptera frugiperda (J. E. Smith, 1797) (Lepidotera:Noctuidae). 1995. Tese (Doutorado em Ciências Biológicas) - Escola Superior de Agricultura "Luiz de Queiroz", Universidade de São Paulo, Piracicaba. 
HUANG， R. C.; OKAMURA， H.; IWAGAWA，T.; TADERA, K.; NAKATANI, M. Azedarachin C, a limonoid antifeedant from Melia azedarach. Phytochemistry, New York, v. 38, n. 3, p. 593-594, Feb. 1995.

HUANG, R. C.; TADERA, K.; YAGI, F.; MINAMI, Y.; OKAMURA, H.; IWAGAWA, T.; NAKATANI, M. Limonoids from Melia azedarach. Phytochemistry, New York, v. 43, n. 3, p. 581-583, Oct. 1996.

LIMA, F. W. N.; OHASHI, O. S.; SOUZA, F. R. S.; GOMES, F. S. Avaliação de acessos de milho para resistência a Spodoptera frugiperda (Smith) (Lepidoptera: Noctuidae) em laboratório. Acta Amazonica, Manaus, v. 36, n. 2, p. 147-150, 2006.

MARGARITIS, L. H.; MAZZINI, M. Structure of the egg. In: HARRISON, F. W.; LOCKE, M. Microscopic anatomy of invertebrates. New York: Wiley-Liss, 1998. cap. 39, p. 995-1037.

MEDEIROS, C. A. M.; BOIÇA JUNIOR, A. L. Efeito da aplicação de extratos aquosos em couve na alimentação de lagartas de Ascia monuste orseis. Bragantia, Campinas, v. 64, n. 4 , p. 633-641, 2005.

MORAGAS, W. M.; SCHNEIDER, M. O. Biocidas: suas propriedades e histórico no Brasil. Caminhos de Geografia, Uberlândia, v. 3, n. 10, p. 26-40, set. 2003. Disponível em: <www.ig.ufu.br/caminhos_de_geografia. html>. Acesso em: 30 ago. 2006.

MORDUE, A. J.; NISBET, A. J. Azadirachtin from the neem tree Azadirachta indica: its action against insects. Anais da Sociedade Entomológica do Brasil, Jaboticabal, v. 29, n. 4, p. 615-632, dez. 2000.

NALIM, D. M. Biologia, nutrição quantitativa e controle de qualidade de populações de Spodoptera frugiperda (J. E. Smith, 1797) (Lepidoptera: Noctuidae) em duas dietas artificiais. 1991. Tese (Doutorado em Ciências Biológicas) - Escola Superior de Agricultura "Luiz de Queiroz", Universidade de São Paulo, Piracicaba.

NATHAN, S. S. Effects of Melia azedarach on nutritional physiology and enzymes activities of the rice leaffolder Cnaphalocrocis medinalis (Guenée) (Lepidoptera: Pyralidae). Pesticide Biochemistry and Physiology, San Diego, v. 84, n. 2, p. 98-108, Feb. 2006.

PERKINS, W. D.; JONES, R. L.; SPARKS, A. N.; WISEMAN, D. R.; SHOW, J. W.; McMILLIAN, W. R. Artificial diet for mass rearing of corn earworm (Heliothis zea). Washington: USDA/ARS, 1973. (Production Report, 154).
ROEL, A. R. A agricultura orgânica ou ecológica e a sustentabilidade da agricultura. Revista Internacional de Desenvolvimento, Campo Grande, v. 3, n. 4, p. 57-62, mar. 2002.

RODRÍGUEZ, H. C.; VENDRAMIM, J. D. Toxicidad de extractos acuosos de Meliaceae en Spodoptera frugiperda (Lepidoptera: Noctuidae). Manejo Integrado de Plagas, Turrialba, v. 42, n. 1, p. 14-22, 1996.

SAITO, M. L.; POTT, A.; FERRAZ, J. M. G.; NASCIMENTO, R. S. Avaliação de plantas com atividade deterrente alimentar em Spodoptera frugiperda (J. E. Smith) e Anticarsia gemmatalis (Hubner). Pesticidas: Revista de Ecotoxicologia e Meio Ambiente, Curitiba, v. 14, p. 1-10, jan./dez. 2004.

SCHMIDT, G. H.; AHMED, A. A. I.; BREUER, M. Effect of Melia azedarach extract on larval development and reproduction parameters of Spodoptera littoralis (Boisd.) and Agrotis ipsilon (Hufn.) (Lep. Noctuidae). Anzeiger fur Schadlingskunde Pflanzenschutz Umweltschutz, Berlin, v. 70, n. 1, p. 4-12, Jan. 1997.

SCHUMUTTERER, H. Properties and potencial of natural pesticides from the neem tree, Azadirachta indica. Annual Review of Entomology, Palo Alto, v. 35,p. 271-297, 1990.

THOMAZINI, A. P. B. W.; VENDRAMIM, J. D.; LOPES, M. T. R. Extratos aquosos de Trichilia pallida e a traça-do-tomateiro. Scientia Agricola, Piracicaba, v. 57, n. 1, p. 13-17, jan./mar. 2000.

TORRECILLAS, S. M.; VENDRAMIM, J. D. Extrato aquoso de ramos de Trichilia pallida e o desenvolvimento de Spodoptera frugiperda em genótipos de milho. Scientia Agricola, Piracicaba, v. 58, n. 1, p. 27-31, jan./ mar. 2001.

TORRES, A. L.; BOIÇA, A. L.; MEDEIROS, C. A. M.; BARROS, R. Efeito de extratos aquosos de Azadirachta indica, Melia azedarach e Aspidosperma pyrifolium no desenvolvimento e oviposição de Plutella xylostella. Bragantia, Campinas, v. 65, n. 3, p. 447-457, 2006.

TORRES, A. L.; BARROS, R.; OLIVEIRA, J. V. Efeito de extratos aquosos de plantas no desenvolvimento de Plutella xylostella (L.) (Lepidoptera: Plutellidae). Neotropical Entomology, Londrina, v. 30, n. 1, p. 151156, mar. 2001.

VALICENTE, F. H. Ocorrência e controle de pragas durante a safra de milho no Sudoeste Goiano. Sete Lagoas: Embrapa Milho e Sorgo, 2004. (Circular Técnica, 47). 
VALICENTE, F. H.; VIANA, P. A.; WAQUIL, J. M. Ocorrência e controle de pragas durante a safrinha de milho no Sudoeste Goiano. Sete Lagoas: Embrapa Milho e Sorgo, 2004. (Circular Técnica, 48).

VIANA, P. A.; WAQUIL, J. M.; VALICENTE, F. H.; CRUZ, I. Ocorrência e controle de pragas na safra de milho nas regiões norte e oeste do Paraná. Sete Lagoas: Embrapa Milho e Sorgo, 2004. (Circular Técnica, 44).

VIANA, P. A.; PRATES, H. T. Desenvolvimento e mortalidade larval de Spodoptera frugiperda em folhas de milho tratadas com extrato aquoso de folhas de Azadirachta indica. Bragantia, Campinas, v. 62, n. 1, p. 69-74, 2003.
VIEGAS JÚNIOR, C. Terpenos com atividades inseticidas: uma alternativa para o controle químico de insetos. Química Nova, São Paulo, v. 26, n. 3, p. 390-400, maio/jun. 2003.

WAQUIL, J. M.; ÁVILA, C. J.; VIANA, P. A.; VALICENTE, F. H.; CRUZ, I. Ocorrência e controle de pragas na cultura do milho no Mato Grosso do Sul - Safrinha. Sete Lagoas: Embrapa Milho e Sorgo, 2004. (Circular Técnica, 46). 
